\title{
Carbon-to-chlorophyll ratio and growth rate of phytoplankton in the sea
}

\author{
Shubha Sathyendranath ${ }^{1,2, *}$, Venetia Stuart ${ }^{2}$, Anitha Nair ${ }^{2}$, Kenji Oka ${ }^{3}$, Toru Nakane ${ }^{4}$, \\ Heather Bouman ${ }^{5}$, Marie-Hélène Forget ${ }^{2}$, Heidi Maass ${ }^{6}$, Trevor Platt ${ }^{1,6}$ \\ ${ }^{1}$ Plymouth Marine Laboratory, Prospect Place, The Hoe, Plymouth PL1 3DH, UK \\ ${ }^{2}$ Department of Oceanography, Dalhousie University, Halifax, Nova Scotia B3H 4J1, Canada \\ ${ }^{3}$ Marine Biological Research Institute of Japan Co. Ltd., 4-3-16, Yutaka-cho, Shinagawa-ku, Tokyo 142, Japan \\ ${ }^{4}$ Science and Technology Co. Ltd., R-Bldg, 1-8-12 Kitashinagawa, Shinagawa-ku, Tokyo 140-0001, Japan \\ ${ }^{5}$ Oxford University, Earth Sciences, Parks Road, Oxford OX1 3PR, UK \\ ${ }^{6}$ Ocean Sciences Division, Bedford Institute of Oceanography, Box 1006, Dartmouth, Nova Scotia B2Y 4A2, Canada
}

\begin{abstract}
Observations from offshore regions (NW Atlantic and Arabian Sea) and from a semienclosed bay (Tokyo Bay) were used to study the relationships between chlorophyll and particulate carbon in the sea. A simple conceptual model was then developed to infer in situ phytoplankton carbon as a function of chlorophyll $a$. This allowed indirect estimates of the carbon-to-chlorophyll ratio of phytoplankton in the sea. Using data from high-performance liquid chromatography, field samples dominated by diatoms, dinoflagellates, green algae, prymnesiophytes and cyanobacteria were identified, and their carbon-to-chlorophyll ratios were established. The computations yielded conservative estimates for the ratio (15 to 176 weight:weight). The results were applied to satellite data to map the carbon-to-chlorophyll ratios in the NW Atlantic. Since methods were already in place to estimate photosynthesis-irradiance parameters for the region by remote sensing (Platt et al. 2008), we showed that it was possible, using remote sensing, to compute carbon-based phytoplankton growth rates by making use of the existing information on photosynthesis-irradiance parameters and carbonto-chlorophyll ratios. The method makes it possible to compute primary production by using either carbon-based growth models or photosynthesis-irradiance models in ways that are fully comparable with each other.
\end{abstract}

KEY WORDS: Phytoplankton - Particulate carbon - Carbon-to-chlorophyll ratio · Growth rates Photosynthesis-Irradiance parameters $\cdot$ Functional types $\cdot$ Remote sensing $\cdot$ Ocean colour

\section{INTRODUCTION}

An important element of most ecosystem models is the computation of primary production. Sathyendranath \& Platt (2007) and Sathyendranath et al. (2007) have pointed out that 4 categories of models are presently in use for the computation of primary production at sea: available-light models, absorbed-light models, inherent-optical-property models and growth models. Regardless of the type of model selected, the computation of primary production at discrete depths requires a set of 4 parameters: (1) the initial slope of the photosynthesis-irradiance curve, (2) the light-saturation parameter of the curve, (3) the specific absorption coefficient of phytoplankton and (4) the carbon-tochlorophyll ratio of phytoplankton. Any other parameter invoked in any primary production model can be derived from this basic set. For models in which phytoplankton are partitioned into several compartments (for example functional types), one needs information on these parameters for each of the compartments. Of the 4 basic parameters, phytoplankton absorption characteristics are routinely measured now on many bio-optical cruises, and our knowledge of their vari- 
ability has been steadily growing (Bricaud et al. 2004, Devred et al. 2006). There is also a growing set of observations at sea of photosynthesis-irradiance parameters (Platt et al. 2008), though they are by no means as numerous as those for optical property measurements. The least studied of our short list of essential parameters turns out to be the carbon-to-chlorophyll ratio of phytoplankton. Improving our understanding of this ratio should provide an opportunity to refine models of phytoplankton dynamics.

Here, we addressed the matter by analysis of previously unpublished data on total particulate carbon and chlorophyll collected in areas extending from the shelf to the open ocean, covering various seasons, and in a semi-enclosed bay (Tokyo Bay) over an annual cycle. Since particulate carbon values from the field included contributions from many components of the ecosystem other than phytoplankton, such as detritus, bacteria and viruses, it was not straightforward to estimate the phytoplankton component of the total particulate carbon. Here, we analysed our dataset to infer phytoplankton carbon-to-chlorophyll ratios across different types of marine and coastal environments. We also examined the data to find systematic differences, if any exist, in this ratio across different phytoplankton types. The relationships established using field data were applied to a satellite-derived chlorophyll field in the NW Atlantic in order to generate maps of particulate carbon, phytoplankton carbon, phytoplankton carbonto-chlorophyll ratios and carbon-based, light-saturated growth rates for phytoplankton, thus demonstrating several applications of the results.

\section{MATERIALS AND METHODS}

Background. Typically, carbon-based growth models of phytoplankton utilise a growth parameter $\mu$, defined as the rate of change of carbon due to photosynthesis per unit time and unit carbon:

$$
\mu=\frac{1}{C_{\mathrm{p}}} \frac{\mathrm{d} C_{\mathrm{p}}}{\mathrm{d} t}
$$

where $C_{\mathrm{p}}$ is the phytoplankton carbon concentration. On the other hand, in chlorophyll-based models, gross primary production $P$ is often computed as a function of available light, using equations such as the following (Platt et al. 1980), in which photo-inhibition is neglected, for simplicity:

$$
P=B P_{m}^{B}\left[1-\exp \left(-\frac{\alpha^{B}}{P_{m}^{B}} E\right)\right]
$$

where $P_{m}^{B}$ is the assimilation number or light-saturation parameter, $\alpha^{B}$ is the initial slope at light-limiting conditions, $B$ is phytoplankton biomass in chlorophyll units, and $E$ is available irradiance in the photosynthetic domain. Since $P=\mathrm{d} C_{\mathrm{p}} / \mathrm{d} t$, we have the equivalence:

$$
\mu=\frac{P}{C_{\mathrm{p}}}=\frac{B P_{m}^{B}}{C_{\mathrm{p}}}\left[1-\exp \left(-\frac{\alpha^{B}}{P_{m}^{B}} E\right)\right]=\frac{P_{m}^{B}}{\chi}\left[1-\exp \left(-\frac{\alpha^{B}}{P_{m}^{B}} E\right)\right]
$$

where $\chi=C_{\mathrm{p}} / B$ is the carbon-to-chlorophyll ratio for phytoplankton. Thus, we need to know $\chi$ if we are to make use of data on photosynthesis-irradiance parameters to constrain growth models at sea. Note that Eqs. (1) to (3) represent gross primary production, and so hold for results of short-term incubation experiments from which losses in production due to dark respiration are not subtracted. Daily growth rates in cultures represent net production (Cloern et al. 1995), and would not be directly applicable to Eq. (3), unless appropriate measures were taken to account for respiration losses. Note also that the photosynthesis-irradiance formalism (Eq. 2) does not require knowledge of $\chi$, unless the intention is to convert estimated $P$ to an increment in chlorophyll biomass $B$.

The carbon-to-chlorophyll ratio is also invoked when fields of phytoplankton carbon computed in global biogeochemical models are converted to fields of chlorophyll $a(\mathrm{chl} a)$, in order to compare them with satellite data for initiation and validation of the models. This is an important application of remotely-sensed ocean colour data, so it is worthwhile to optimise the protocol for the computation of phytoplankton carbon.

Data and analysis. Offshore data: Over a period of more than a decade, particulate carbon and phytoplankton pigment data (fluorometric chl $a$ and HPLC pigments) were collected from 16 cruises to shelf and open-ocean waters, mostly from the NW Atlantic, but also from the Arabian Sea. The geographical areas and periods of data collection and the number of samples collected are summarised in Table 1.

Water samples were collected, using Niskin bottles, from the surface to a maximum sample depth of $80 \mathrm{~m}$ (most of the samples [>90\%] were from depths of $40 \mathrm{~m}$ or less). Particulate carbon samples were analysed with a CHN analyser (Collos 2002), and may be considered to consist primarily of particulate organic carbon (POC). Estimates of fluorometric chl a concentrations were obtained using a Turner Designs fluorometer following the method of Holm-Hansen et al. (1965). Samples were also analyzed by high-performance liquid chromatography (HPLC), in order to obtain information on the composition of the accessory pigments. Between 0.5 and $1.5 \mathrm{l}$ of seawater was filtered onto a $25 \mathrm{~mm} \mathrm{GF} / \mathrm{F}$ filter, which was frozen in liquid nitrogen and stored at $-80^{\circ} \mathrm{C}$ until analysis in the laboratory using the method of Stuart \& Head (2005).

The HPLC pigment data were used to identify samples that were dominated by diatoms, dinoflagellates, 
Table 1. Details of the 16 shelf and open-ocean cruises (offshore data) where samples were collected for chlorophyll and carbon measurements, showing geographic area, sampling dates and total number of samples (n) collectedon each cruise

\begin{tabular}{|llc|}
\hline Area & Dates & $\mathrm{n}$ \\
\hline Arabian Sea (Tyro Cruise) & 13 Jan-4 Feb 1993 & 17 \\
Arabian Sea (Arabesque 1 Cruise) & 28 Aug-30 Sep 1994 & 110 \\
Arabian Sea (Arabesque 2 Cruise) & 17 Nov-15 Dec 1994 & 95 \\
Labrador Sea (JGOFS Cruise) & 15 May-30 May 1996 & 45 \\
Labrador Sea (JGOFS Cruise) & 24 Oct-17 Nov 1996 & 28 \\
Scotian Shelf (Hudson Cruise) & 18 Apr-28 Apr 1997 & 16 \\
Labrador Sea (JGOFS Cruise) & 12 May-9 Jun 1997 & 50 \\
Scotian Shelf (Hudson Cruise) & 8 Apr-21 Apr 1998 & 26 \\
Scotian Shelf (Hudson Cruise) & 3 Oct-20 Oct 1998 & 30 \\
Scotian Shelf (Hudson Cruise) & 9 Apr-17 Apr 1999 & 39 \\
Scotian Shelf (Hudson Cruise) & 24 Oct-12 Nov 1999 & 37 \\
Scotian Shelf (Hudson Cruise) & 9 Apr-22 Apr 2000 & 49 \\
Scotian Shelf (Hudson, Cruise) & 1 Oct-15 Oct 2000 & 98 \\
Scotian Shelf (Hudson, Cruise) & 2 May-16 May 2001 & 105 \\
Labrador Sea (Hudson Cruise) & 31 May-13 Jun 2001 & 42 \\
Scotian Shelf (Hudson Cruise) & 24 Oct-7 Nov 2001 & 60 \\
Total & & 847 \\
\hline
\end{tabular}

prymnesiophytes, Prochlorococcus, other cyanobacteria (e.g. Synechococcus) and green algae. The pigment criteria used to identify these algal groups are shown in Table 2.

Since, for the same particulate carbon samples, corresponding chl a estimates were available using both the Turner fluorometric method $\left(B_{\mathrm{F}}\right)$ and the HPLC method $\left(B_{\mathrm{H}}\right)$, the relationships between particulate carbon and chl a were explored separately for the 2 chlorophyll estimates, especially because some systematic differences were often encountered between the chl a values estimated by the 2 methods (e.g. $\mathrm{r}^{2}=$ 0.89 , slope $=1.39, \mathrm{n}=814$, for linear regression of HPLC chlorophyll and Turner fluorometric chlorophyll for our offshore data set). Both particulate carbon and chl a data were log-transformed to linearise the relationship and to reduce the weight of the stations with high values of particulate carbon and chl $a$ in the regression analysis (see also Legendre \& Michaud 1999). Ordinary least-squares regression analysis was carried out with particulate carbon as the dependent variable and $B_{\mathrm{F}}$ or $B_{\mathrm{H}}$ as the independent variable. If we represent total particulate carbon by $C_{\mathrm{T}}$, then the fitted equations have the form: $\log \left(C_{\mathrm{T}}\right)=\log m+p(\log$ $\left.B_{i}\right)$, where $i=H$ or $F$, and $\log m$ and $p$ are the fitted parameters. The results can then be expressed as:

$$
C_{\mathrm{T}}=m B_{i}^{p}
$$

Tokyo Bay data: Particulate carbon and pigment data were collected at 3 stations in Tokyo Bay every month from August 1997 until July 2000. Water samples were collected, using 51 Van-Dorn bottles, at 7 to 8 depths throughout the water column (maximum depth $30 \mathrm{~m}$ ). Particulate carbon, fluorometric chl a concentration and HPLC pigment composition were measured at each sampling depth as described above (HPLC samples were collected within the top $10 \mathrm{~m}$ only). In the offshore dataset, HPLC pigments were used to identify samples dominated by any 1 of 6 phytoplankton functional types. It emerged that, when our criteria were applied to identify algal groups, this set of observations included samples dominated by diatoms and dinoflagellates, but none of the other types (Table 2). Again, the relationships between carbon and chl a were estimated for Turner fluorometric chl $a$ and HPLC chl a separately.

Satellite data: Local-area coverage SeaWiFS data collected during the period from 1997 to 2006 at the Bedford Institute of Oceanography were used to generate bimonthly composite maps of chlorophyll using the NASA OC4 algorithm (O'Reilly et al. 2000) and SeaDAS software. The composites for the second half of May for all years were then combined to create a climatological chlorophyll map for this time interval, which was then used to illustrate how the results established from the field data could be used to arrive at first-order estimates on the distribution of particulate carbon, phytoplankton carbon, carbon-tochlorophyll ratios $(\chi)$ and carbon-based growth rates for phytoplankton.

Quantile regression: For a given observation of particulate carbon in the ocean, the result may be partitioned into a portion that corresponds to the living organic carbon contained in phytoplankton and a residual that includes contributions from heterotrophs and various sources of detritus. Addition of any of these components other than phytoplankton would increase total particulate carbon without increasing chlorophyll. Therefore, we assumed that, at any given chlorophyll concentration, the lowest particulate carbon content observed represents the phytoplankton carbon associated with that chlorophyll concentration. Given such data over a range of chlorophyll concentrations, we sought the relationship between the phytoplankton carbon concentration (as opposed to total particulate carbon) and the chlorophyll concentration. This relationship can be represented as a line forming a lower envelope to the values of total particulate carbon plotted as a function of chlorophyll concentration. The appropriate method to find this relation is quantile regression (Koenker \& Bassett 1978). At the same time, we want to exclude any outliers that, through measurement error, are biased too low to belong to the parent distribution. 
Table 2. Criteria used to omit samples from the database in order to identify various phytoplankton types. These criteria require that the concentrations of pigments diagnostic for a particular type of phytoplankton should be high relative to the concentration of chlorophyll $a$, while, at the same time, the relative concentrations of diagnostic pigments for other types of phytoplankton should be low. Collectively, the criteria identify those samples in which a single phytoplankton type may be assumed to dominate, based on the chemotaxonomic signature. Chl: chlorophyll; Hex: 19'-hexanoyloxyfucoxanthin; But: 19'-butanoyloxyfucoxanthin

\begin{tabular}{|c|c|c|}
\hline Phytoplankton type & $\begin{array}{l}\text { Criteria for omitting samp } \\
\text { not belonging to a type }\end{array}$ & \\
\hline Prymnesiophytes & $\begin{array}{l}\mathrm{Chl} \mathrm{C}_{3} / \mathrm{Chl} a \\
\% \text { Divinyl Chl } a \text { and } b \\
\text { Zeaxanthin/Chl } a \\
\text { Peridinin/Chl } a \\
\text { Alloxanthin/Chl } a \\
\text { Chl } b / \mathrm{Chl} a \\
\text { Hex/Chl } a \text { and But/Chl } a\end{array}$ & $\begin{array}{l}<0.035 \\
>10 \% \\
>0.01 \\
>0.1 \\
>0.01 \\
>0.1 \\
<0.05\end{array}$ \\
\hline Prochlorococcus sp. & $\begin{array}{l}\text { \% Divinyl Chl } a \text { and } b \\
\text { Fucoxanthin/Chl } a \\
\text { Chl } c_{3} / \mathrm{Chl} a \\
\text { Hex/Chl } a\end{array}$ & $\begin{array}{l}<50 \% \\
>0.01 \\
>0.01 \\
>0.2\end{array}$ \\
\hline Diatoms & $\begin{array}{l}\text { Fucoxanthin/Chl } a \\
\text { Chl } c_{1,2} / \mathrm{Chl} a \\
\text { Chl } c_{3} / \mathrm{Chl} a \\
\text { Zeaxanthin/Chl } a \\
\text { Hex/Chl } a \\
\text { Chl } b / \mathrm{Chl} a \\
\text { Diadinoxanthin/Chl } a\end{array}$ & $\begin{array}{l}<0.4 \\
<0.1 \\
>0.01 \\
>0.01 \\
>0.1 \\
>0.1 \\
<0.01\end{array}$ \\
\hline Cyanobacteria & $\begin{array}{l}\text { Zeaxanthin/Chl a } \\
\text { \% Divinyl Chl } a \\
\text { Fucoxanthin/Chl } a \\
\text { Chl } b / \mathrm{Chl} a \\
\text { Peridinin/Chl a } \\
\mathrm{Hex} / \mathrm{Chl} a \\
\mathrm{Chl} C_{3} / \mathrm{Chl} a\end{array}$ & $\begin{array}{l}<0.1 \\
>20 \% \\
>0.1 \\
>0.2 \\
>0.03 \\
>0.2 \\
>0.035\end{array}$ \\
\hline Green algae & $\begin{array}{l}\text { Chl } b / \mathrm{Chl} a \\
\% \text { Divinyl Chl } b \text { and } b \\
\text { Fucoxanthin/Chl } a \\
\text { Chl } c_{1,2} / \mathrm{Chl} a \\
\text { Hex/Chl } a \\
\text { Alloxanthin/Chl } a\end{array}$ & $\begin{array}{l}<0.1 \\
>10 \% \\
>0.01 \\
>0.1 \\
>0.2 \\
>0.05\end{array}$ \\
\hline Dinoflagellates & $\begin{array}{l}\text { Fucoxanthin/Chl } a \\
\text { Peridinin/Chl } a \\
\text { Hex/Chl } a \\
\text { Chl } b / \mathrm{Chl} a\end{array}$ & $\begin{array}{l}<0.25 \\
<0.4 \\
>0.2 \\
>0.1\end{array}$ \\
\hline
\end{tabular}

For example, the 50th percentile (median, $q=0.5$ ) regression is a fitted line for which half the observations of the dependent variable lie above and half below. The line represented by the 5th percentile regression lies below $95 \%$ of the observations. Clearly, to find the desired lower range, we sought such a loworder quantile regression. In fact, we sought the regression for the lowest quantile consistent with the criterion of robustness. Rogers (1992) advises that the minimum quantile $q$ should satisfy the condition $q>$
$5 / N$, where $N$ is the total number of observations. With some 800 observations, this working rule would allow a regression at the first percentile $(q=0.01)$, but not much lower.

The other fitting criterion is derived from inspection of the (log-transformed to base 10) data. It is clear that they are convergent from lower to higher values of chlorophyll, an indication that phytoplankton carbon constitutes a higher proportion of particulate carbon as chlorophyll concentration increases and approaches that characteristic of bloom conditions. In fitting the $q=$ 0.01 regression, we required that the fitted slope reflected this evident convergence. Therefore, if the fitted slope for the $q=0.01$ regression was smaller than that of the $q=0.02$ regression, we omitted the observation with the largest residual and refitted the lines. The procedure was repeated iteratively until the slope exceeded or equalled that of the $q=0.02$ regression. In this way, 3 (HPLC) to 8 (Turner fluorometer) data points were identified as outliers in the offshore dataset. The final fit was judged to be free of bias by outliers and to be the best available linear description of the lower edge of the scatter plot for the log-transformed data.

\section{RESULTS}

\section{Offshore data}

The straight-line fits to the log-transformed offshore data are shown in Fig. 1 for particulate carbon plotted as a function of both Turner fluorometric chl $a$ and HPLC chl a (see also Table 3). The method of Legendre \& Michaud (1999), who also analysed the relationship between POC and chl $a$, is slightly different from ours in the sense that they integrated POC and chl $a$ over a finite depth of the water column and then used average values of the variables over the depth of integration in the regression analysis. Our analyses, on the other hand, are based on discrete-depth samples. Our results for the parameters $\log m$ and $p$ for the offshore data are remarkably close to the values reported by Legendre \& Michaud (1999) for all station depths (Table 3) for POC.

The particulate carbon field data incorporate all types of carbon in the system, including that from phytoplankton, detritus, bacteria and viruses that are retained on the filter. We can assume that the minimum carbon amount associated with each concentration of chl a represents the phytoplankton carbon, any other particulate carbon serving to increase the measured carbon over the minimum. Using quantile regression (for $q=0.01$ ), we therefore fitted a line (Fig. 1) that follows the minimum values of particulate 


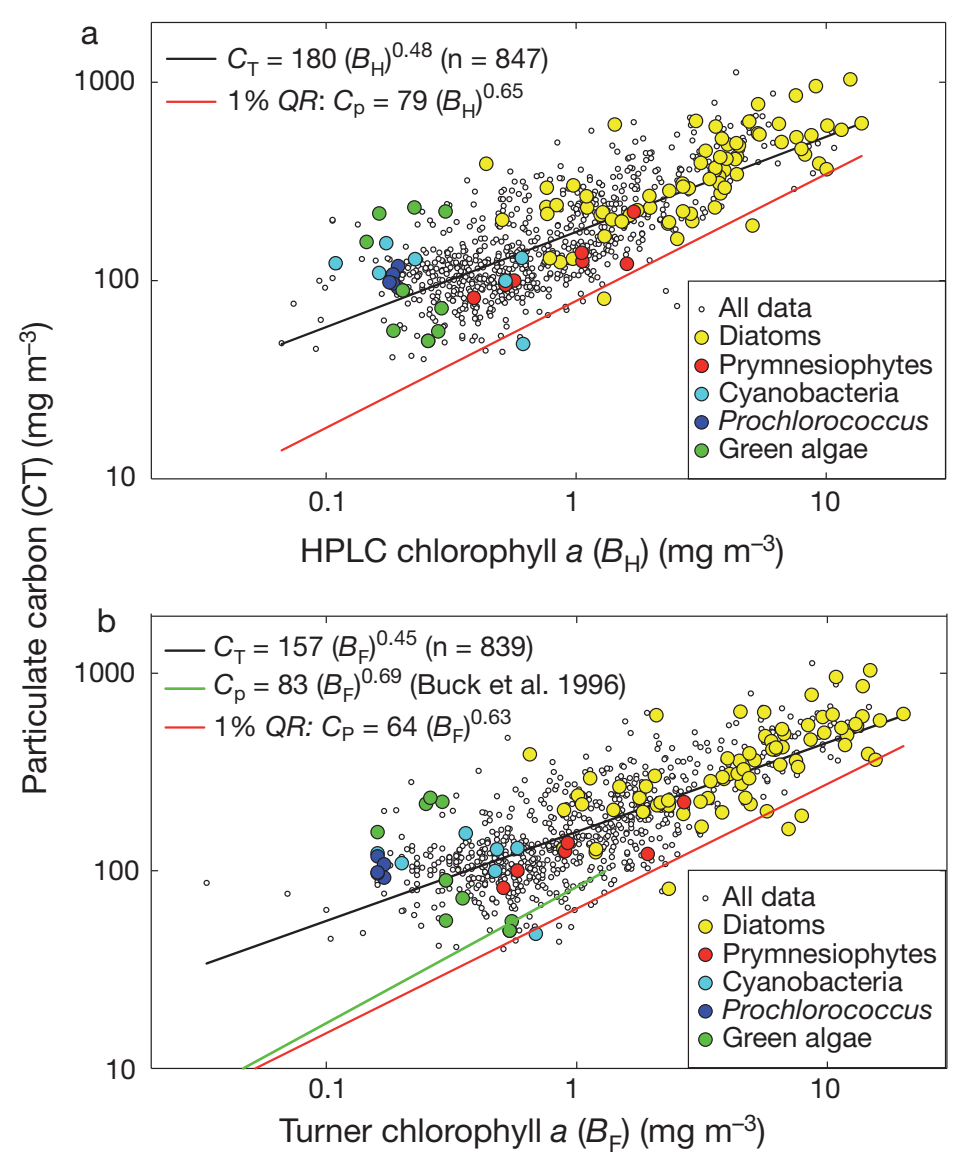

Fig. 1. Particulate carbon $\left(C_{\mathrm{T}}\right)$ as a function of chlorophyll a for offshore data. Chlorophyll a estimated by (a) HPLC and (b) Turner fluorometer. Least-squares fits to log-transformed data are shown, as well as minimum carbon estimates $\left(C_{\mathrm{p}}\right.$, by quantile regression $\left.[\mathrm{QR}] q=0.01\right)$, which may be interpreted as the upper limits for phytoplankton carbon in the system. The relationship between phytoplankton carbon and chlorophyll $a$ in field data (Buck et al. 1996) is also shown in (b). The samples identified as being dominated by a particular type of phytoplankton are identified by different colours

carbon associated with any given chl a concentration (ignoring identified outliers). Since phytoplankton contribution to total particulate carbon may be expected to increase from oligotrophic to eutrophic waters, we anticipated that the lines representing total and phytoplankton carbon would approach each other at high chlorophyll concentrations. The equations for estimating phytoplankton carbon from chl a concentration are also given in Table 3 for both Turner fluorometric and HPLC pigment data. From these equations, one can estimate $\chi$, the carbon-to-chlorophyll ratio of phytoplankton, and its variation with chl a.

Since the data set contains information on the pigment composition of phytoplankton, samples dominated by a single phytoplankton type could be identified based on their diagnostic pigments. These phytoplankton types are fairly well separated along the chlorophyll axis, with samples dominated by Prochlorococcus, other cyanobacteria and green algae appearing in oligotrophic waters, and diatoms and prymnesiophytes becoming more dominant in high-chlorophyll waters. No dinoflagellatedominated samples were identified from this data set according to the criteria outlined in Table 2. Using the chlorophyll concentrations of the samples and Eqs. (7) \& (8) from Table 3 for HPLC and Turner fluorometer data, respectively, one can compute $\chi$ for these samples. The averages and ranges of $\chi$ for the 5 phytoplankton types identified are presented in Table 4. These numbers are consistent with values in the literature on the carbon-tochlorophyll ratios for various phytoplankton types (Malone 1982, Geider 1987, Campbell et al. 1994, Kuninao et al. 2000, Schoemann et al. 2005, Veldhuis et al. 2005), providing indirect validation of our method.

The shape of the cloud of points above the minimum relationship (Fig. 1) is consistent with the interpretation that there would be a more variable contribution to the particulate carbon from material other than phytoplankton in oligotrophic waters, whereas the relationship between particulate carbon and phytoplankton carbon would be tighter at higher chlorophyll concentrations. Note also that the parameter $p$ is $<1$, that is, particulate carbon increases less rapidly than chl $a$, which could be a consequence of the greater contribution of phytoplankton to the total particulate carbon pool in eutrophic, compared with oligotrophic, conditions. This would also provide an explanation for the decrease in scatter in the relationship at higher chl a concentrations.

Buck et al. (1996) proposed a relationship (green line in Fig. 1b) for estimating phytoplankton carbon as a function of chl a concentration, based on observations at sea. The correspondence between this relationship and Eq. (8) (Table 3) is excellent for chlorophyll concentrations of about $1 \mathrm{mg} \mathrm{m}^{-3}$ or less, for which the Buck et al. (1996) relationship was established. If we extrapolated the equation by Buck et al. (1996) towards higher chlorophyll concentrations, the line would intersect our best fit between particulate carbon and chlorophyll at a chlorophyll concentration of about $10 \mathrm{mg} \mathrm{m} \mathrm{m}^{-3}$. Because phytoplankton carbon cannot be greater than the total community carbon, the minimum relationship applied to our data arguably provides a better estimate of phytoplankton carbon for high chlorophyll values than the extrapolated relationship from Buck et al. (1996). 
Table 3. Fitted relationships between log carbon and log chlorophyll in the field for Turner fluorometric chlorophyll a ( $\left.B_{\mathrm{F}}\right)$ and HPLC chlorophyll a $\left(B_{\mathrm{H}}\right)$. Total particulate carbon is represented as $C_{\mathrm{T}}$, and $C_{\mathrm{p}}$ is the estimated phytoplankton carbon. The fits to $\log C_{\mathrm{T}}$ are by standard linear least-squares regression. The fits to estimate $\log C_{\mathrm{p}}$ are the results of $1 \%$ quantile regression, after elimination of outliers. Results from Morel (1988), Legendre \& Michaud (1999) and Buck et al. (1996) are also given, for comparison. Number of observations (n) and $\mathrm{r}^{2}$ values are also given for $\log -\log$ regressions. Note that the fitted relationships are of the form $\log (Y)=\log (m)+p[\log (X)]$. POC: particulate organic carbon

\begin{tabular}{|lcccccccl|}
\hline & $x$ & $y$ & $\log (m)$ & $\mathrm{p}$ & $\mathrm{n}$ & $\mathrm{r}^{2}$ & Eq. No. & Source \\
\hline Offshore (HPLC) & $B_{\mathrm{H}}$ & $C_{\mathrm{T}}$ & $2.26 \pm 0.006$ & $0.48 \pm 0.014$ & 847 & 0.58 & 5 & In situ data \\
Offshore (Turner) & $B_{\mathrm{F}}$ & $C_{\mathrm{T}}$ & $2.20 \pm 0.006$ & $0.45 \pm 0.013$ & 839 & 0.59 & 6 & In situ data \\
Offshore (HPLC) & $B_{\mathrm{H}}$ & $C_{\mathrm{p}}$ & 1.90 & 0.65 & 844 & & 7 & In situ data \\
Offshore (Turner) & $B_{\mathrm{F}}$ & $C_{\mathrm{p}}$ & 1.81 & 0.63 & 831 & & 8 & In situ data \\
Tokyo Bay (HPLC) & $B_{\mathrm{H}}$ & $C_{\mathrm{T}}$ & $2.43 \pm 0.014$ & $0.64 \pm 0.017$ & 469 & 0.76 & 9 & In situ data \\
Tokyo Bay (Turner) & $B_{\mathrm{F}}$ & $C_{\mathrm{T}}$ & $2.41 \pm 0.010$ & $0.60 \pm 0.011$ & 811 & 0.78 & 10 & In situ data \\
North Atlantic & $B_{\mathrm{F}}$ & $C_{\mathrm{p}}$ & 1.92 & 0.69 & & 0.60 & 12 & Buck et al. (1996) \\
Euphotic layer & $B_{\mathrm{F}}$ & POC & 1.95 & 0.57 & 409 & 0.68 & 11 & Morel (1988) \\
All station depths & $B_{\mathrm{F}}$ & POC & $2.21 \pm 0.0140$ & $0.505 \pm 0.021$ & 510 & 0.54 & 13 & Legendre \& Michaud (1999) \\
Station depth <200 m & $B_{\mathrm{F}}$ & POC & $2.29 \pm 0.0194$ & $0.353 \pm 0.033$ & 222 & 0.34 & 14 & Legendre \& Michaud (1999) \\
Station depth $>300 \mathrm{~m}$ & $B_{\mathrm{F}}$ & POC & $2.16 \pm 0.0213$ & $0.614 \pm 0.029$ & 240 & 0.65 & 15 & Legendre \& Michaud (1999) \\
\hline
\end{tabular}

Table 4. Mean and range of the carbon-to-chlorophyll ratios $(\chi)$ of different phytoplankton types, using the results of the $1 \%$ quantile regression (QR). Chl a was determined using a Turner fluorometer and HPLC

\begin{tabular}{|lcc|}
\hline Phytoplankton type & $\begin{array}{c}\text { Mean } \chi(\mathrm{g} / \mathrm{g}) \\
1 \% \mathrm{QR}\end{array}$ & $\begin{array}{c}\text { Range } \chi(\mathrm{g} / \mathrm{g}) \\
1 \% \mathrm{QR}\end{array}$ \\
\hline Turner fluorometer & & \\
Diatoms (Offshore) & 39 & $21-75$ \\
Diatoms (Tokyo Bay) & 29 & $15-55$ \\
Dinoflagellates (Tokyo Bay) & 34 & $22-62$ \\
Prymnesiophytes & 65 & $44-82$ \\
Cyanobacteria & 93 & $74-126$ \\
Green algae & 99 & $80-126$ \\
Prochlorococcus sp. & 125 & $123-126$ \\
All diatoms together & 34 & $15-75$ \\
& & \\
HPLC & & \\
Diatoms (Offshore) & 56 & $31-107$ \\
Diatoms (Tokyo Bay) & 39 & $20-68$ \\
Dinoflagellates (Tokyo Bay) & 45 & $27-80$ \\
Prymnesiophytes & 85 & $65-111$ \\
Cyanobacteria & 130 & $95-176$ \\
Green algae & 137 & $122-159$ \\
Prochlorococcus sp. & 145 & $143-147$ \\
All diatoms together & 47 & $20-107$ \\
\end{tabular}

The mean $( \pm \mathrm{SD})$ fraction of phytoplankton carbon in particulate carbon estimated by this method is $45 \pm$ $21 \%$ using Turner fluorometric chlorophyll data (or 46 $\pm 20 \%$ using HPLC data), which is on the high side, but within the range of values reported in the literature (Eppley et al. 1992, Buck et al. 1996, DuRand et al. 2001, Oubelkheir et al. 2005). On the other hand, $\chi$ values obtained by this simple method (Table 4) compare reasonably well with values in the literature on differ- ent phytoplankton types. Furthermore, the relationship is also consistent with that observed by Buck et al. (1996), suggesting that the estimates of the phytoplankton carbon-to-chlorophyll relationship in the marine environment provided here are reasonable. Note that, based on the equations for phytoplankton carbon and total particulate carbon, the fraction of phytoplankton carbon in the total particulate carbon can be estimated as a function of chlorophyll concentration $\left(C_{\mathrm{p}} / C_{\mathrm{T}}=0.44 B_{\mathrm{H}}^{0.17}\right.$ for HPLC data and $C_{\mathrm{p}} / C_{\mathrm{T}}=$ $0.41 B_{\mathrm{F}}{ }^{0.18}$ for Turner fluorometer data).

\section{Tokyo Bay data}

The Tokyo Bay data yielded higher values of both the parameters $m$ and $p$ for particulate carbon $C_{\mathrm{T}}$ as a function of chl $a$, compared with the offshore data (Fig. 2, Table 3). This suggests the influence of a higher background of non-phytoplankton carbon. The relationships between phytoplankton carbon and chl a established for the offshore data by Turner fluorometric and HPLC pigments (Fig. 1) are also extended here for the higher chlorophyll concentrations encountered in the semi-enclosed bay. The separation between the extrapolated phytoplankton-carbon-chlorophyll lines and the data points in Fig. 2 also suggest that nonphytoplankton contributions to the POC are higher in the coastal environment than in the open ocean, which may be expected for areas influenced by river outflow and land drainage. Analyses of HPLC data revealed that this data set contained samples dominated by diatoms and dinoflagellates. Those samples are identified in Fig. 2, and their carbon-to-chlorophyll ratios are presented in Table 4. 


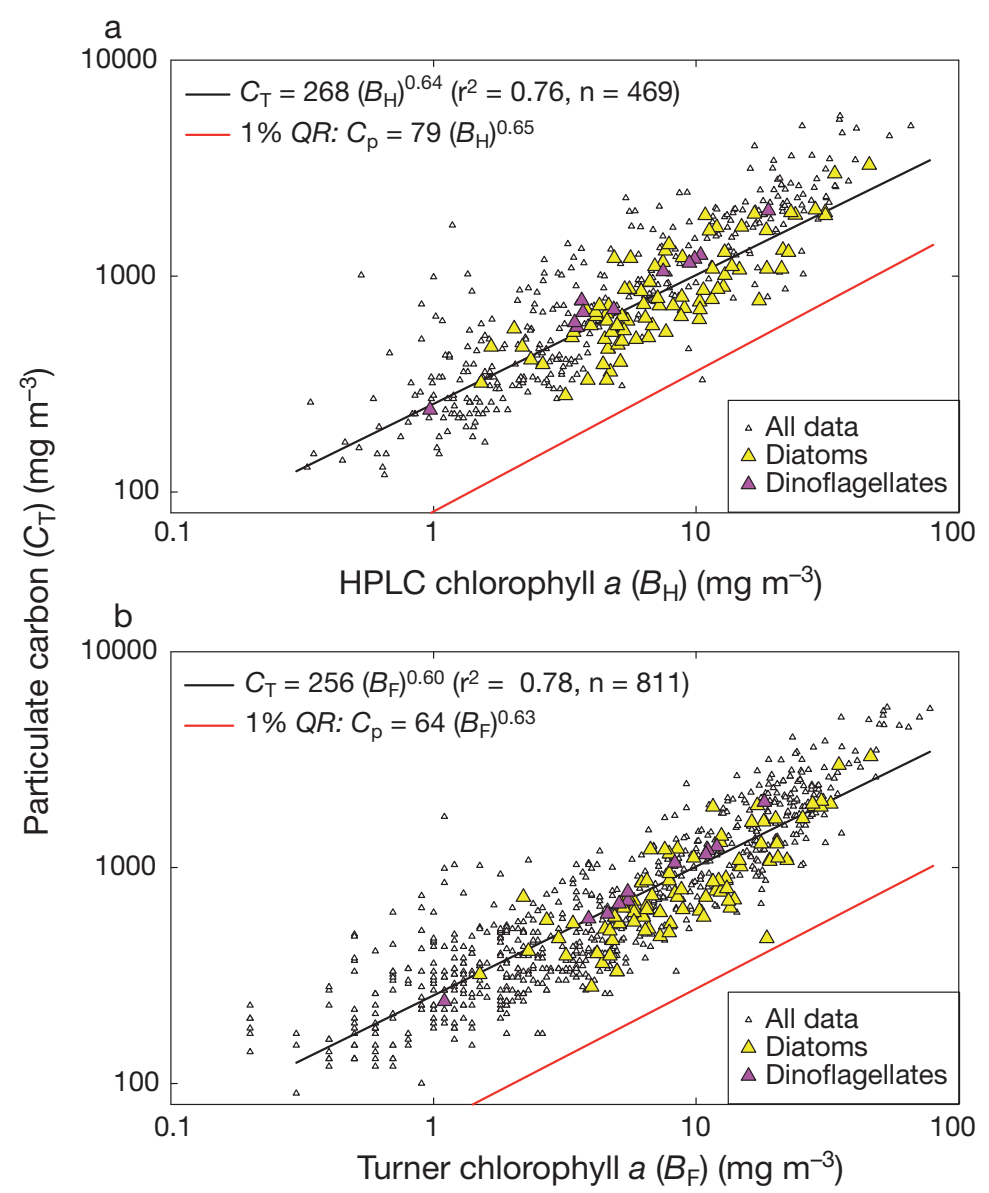

Fig. 2. Particulate carbon $\left(C_{\mathrm{T}}\right)$ as a function of chlorophyll a for a semienclosed basin (Tokyo Bay). Chlorophyll a estimated by (a) HPLC and (b) Turner fluorometer. Least-squares fits to log-transformed data are shown, as well as the minimum carbon estimates $\left(C_{\mathrm{p}}\right)$ from Fig. 1

\section{Satellite-based maps}

To illustrate the potential applications of this work, the results presented above were used in conjunction with chl a estimates derived from SeaWiFS to map particulate carbon, phytoplankton carbon and carbonto-chlorophyll ratios of phytoplankton (Fig. 3) in May in the NW Atlantic. This is the spring bloom season, and the chlorophyll distribution is highly variable (Fig. 3a), ranging from oligotrophic Gulf Stream waters to high chlorophyll waters off SW Greenland. The map of particulate carbon is based on Eq. (6) (Table 3) for offshore data, which relies on a large number of observations from the area. It is an alternative approach to that based on back-scattering (e.g. Loisel et al. 2002) or the method of Gardner et al. (2006), which is based on relationships between beam attenuation, POC and the diffuse attenuation coefficient at $490 \mathrm{~nm}$. Our method is designed to capture the particulate carbon that covaries with $\mathrm{chl} a$. It is not capable of identifying variations in particulate carbon that are independent of chl a. On the other hand, our method is unlikely to be influenced by phenomena such as coccolith blooms or bubbles, which can increase backscattering or the attenuation coefficient without increasing chlorophyll concentration. The maps of particulate carbon and phytoplankton carbon reveal similarities with the chlorophyll map, given the correlation between these properties. The phytoplankton carbon map (using Eq. 8; Table 3) relies, in addition, on a simple conceptual model, which has been tested indirectly by comparison with values from the literature (Buck et al. 1996). The ratio $\chi$ estimated here has a conservative range (10 to 150) and is low in high-biomass areas and high in low-biomass areas. In Fig. 3, we also show the assimilation number $P_{m}^{B}$ computed using the Nearest-Neighbour Method of Platt et al. (2008) and the maximum, light-saturated growth rate, which is computed as $P_{m}^{B} / \chi$ (see Eq. 3). Note that both $P_{m}^{B}$ and the maximum growth rate peak in frontal areas, possibly because of associated high nutrient supply.

\section{DISCUSSION}

\section{Relationship between particulate carbon and chl a concentration}

The data presented here show a strong correlation between particulate carbon and chl $a$ concentration. The results are remarkably close to those presented by Legendre \& Michaud (1999) for an independent data set on POC and chl $a$. They noted that, since chl $a$ is readily estimated from satellite data, such relationships provide a simple avenue for estimating POC from satellite data. They also pointed out the importance of POC in ecosystem models as the food source for zooplankton. Our data also show that our method is robust, even though it straddles a broad range of trophic conditions, ranging from oligotrophic to eutrophic. Such macro-ecological patterns, which appear to transcend boundaries of biogeochemical provinces and even biomes, can also serve as useful tools for testing the performance of marine ecosystem models. Typically, particulate carbon or POC is not represented explicitly in ecosystem models, but can be estimated as the sum of the computed particulate carbon in the various elements of the model, including detritus. If the models were able to reproduce the bulk properties of the ecosystem, as shown here, we would 

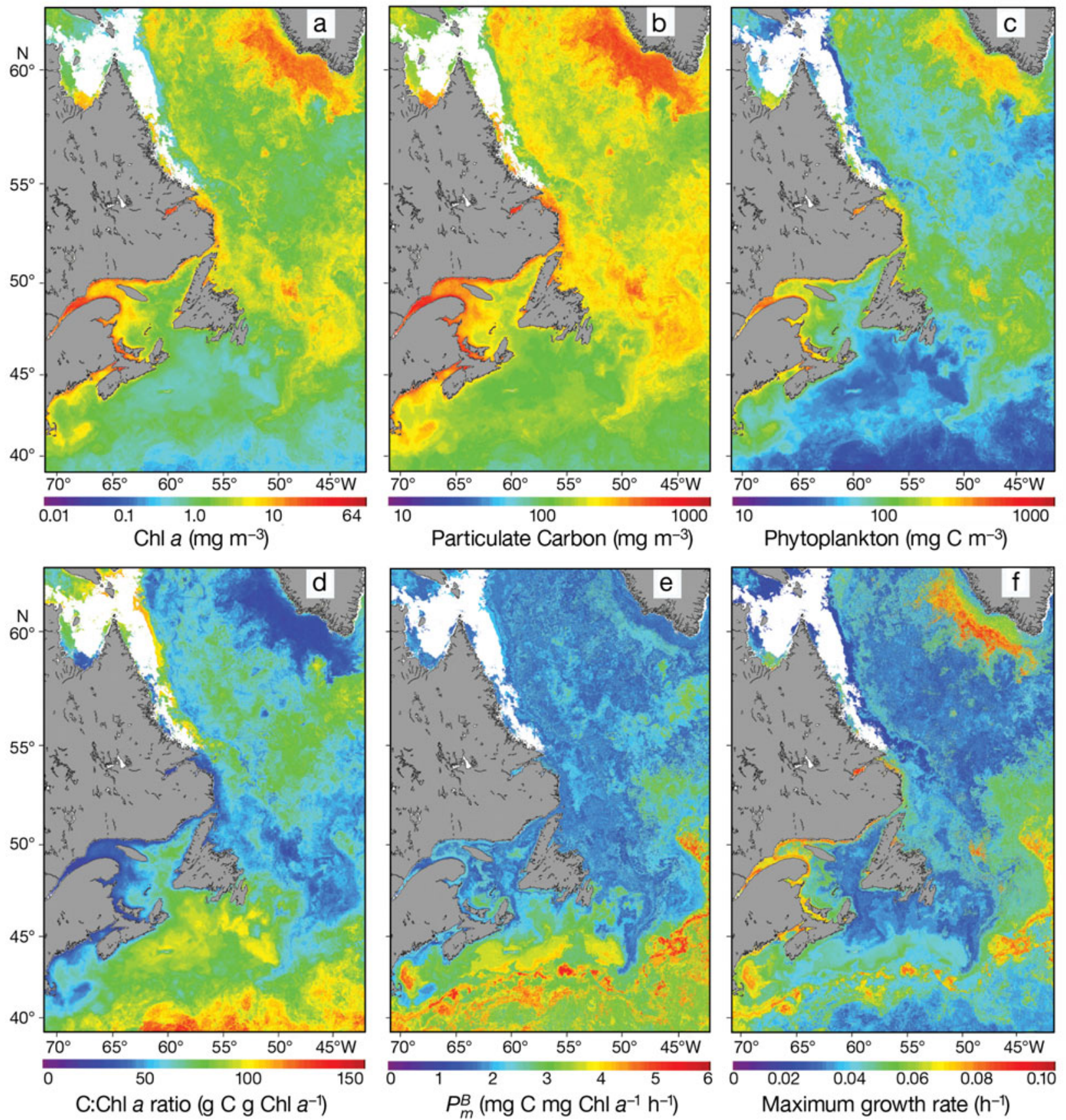

Fig. 3. Climatological chlorophyll a data (1997 to 2006) for the second half of May for the NW Atlantic, derived from SeaWiFS (a). (b) Particulate carbon and (c) estimated fields of phytoplankton carbon $\left(C_{\mathrm{p}}\right)$ derived from (a) using Eq. (7) from Table 3. The chlorophyll and phytoplankton carbon fields are then used to derive $\chi$, the carbon-to-chlorophyll ratio of phytoplankton (d). The Nearest-Neighbour Method of Platt et al. (2008) is used to map the light saturation parameter $P_{m}^{B}$ (e). Finally, $P_{m}^{B}$ is divided by $\chi$ to estimate maximum (light-saturated) carbon growth rates $(\mu)$ using Eq. (3), and setting the terms in parentheses on the right-hand side of the equation to 1 (f)

have an independent validation of the overall performance of the model. One anticipates that macroecological patterns, such as those presented here, would be modulated locally and regionally (as seen, for example, in the differences between offshore and Tokyo Bay data).

\section{Phytoplankton carbon measurement in the field}

Many ecosystem models are not based on chl $a$, but on carbon, such that a suitable carbon-to-chlorophyll ratio has to be invoked to estimate chl a for comparison with satellite data. For phytoplankton at sea, the carbon-to- 
chlorophyll ratio is a poorly known quantity. Phytoplankton carbon concentration is not easily measured in the field, given the difficulty of distinguishing phytoplankton carbon from other types of carbon. What is often measured is the total particulate carbon or POC, of which phytoplankton carbon is recognised to be a variable fraction (Eppley et al. 1992, Oubelkheir et al. 2005). Linear regression of POC on chlorophyll has been used to derive the phytoplankton fraction of the carbon from the slope of the fit, on the assumption that there is a background of POC at sea that is not associated with phytoplankton (e.g. Steele \& Baird 1961, Townsend \& Thomas 2002, Behrenfeld et al. 2005). But the method ignores the possibility that this background might be variable and that other types of particulate carbon might co-vary with the phytoplankton, leading to erroneous results (Banse 1977, Eppley et al. 1992, Legendre \& Michaud 1999), especially when dealing with large data sets from a variety of locations covering a wide range of chl a values, as is the case here. The non-linear approach used here overcomes some of the limitations of these earlier methods.

Oubelkheir et al. (2005) used an analysis of optical data and phytoplankton carbon measurements in cultures to derive the fraction of phytoplankton carbon in POC. Their method has not yet been validated by direct measurements. Another approach to estimating phytoplankton carbon at sea relies on measurements of cell carbon in various types of phytoplankton in laboratory cultures, combined with cell counts of the phytoplankton types at sea (Eppley et al. 1992, DuRand et al. 2001, Grob et al. 2007). The limitation of this method is that the cell quota of carbon is a variable quantity that depends on growth conditions (Geider 1987, Cloern et al. 1995), and this often introduces a level of uncertainty into the calculations. A direct method to estimate the carbon-to-chlorophyll ratio $(\chi)$ at sea is the pigment-labelling method (Goericke \& Welschmeyer 1998). Unfortunately, this method has not yet been widely used.

The variability observed in the relationship between total carbon and chlorophyll (Figs. $1 \& 2$ ) arises from 2 main sources: variability in the proportion of non-phytoplanktonic particulate carbon and variability in the phytoplankton carbon itself. The former type of variability is related to the status of the ecosystem as a whole, whereas the latter may be associated with changes in the phytoplankton community itself or with its acclimation to the light or nutrient regime. Assuming that, at any given chlorophyll concentration, the variability in the total carbon-to-chlorophyll ratio is primarily due to changes in the non-phytoplanktonic carbon, data on total particulate carbon and chlorophyll can be used to retrieve the phytoplankton carbon, as demonstrated here. The estimates we have given for phytoplankton carbon in the field have been derived from measurements of particu- late carbon, invoking simple ecosystem considerations. Since there will always be some contribution to particulate carbon in the field from material other than phytoplankton, this estimate (Eqs. 7 \& 8; Table 3) represents an upper limit of phytoplankton carbon for a given chl a concentration. Moreover, it is well known that adaptation to low light levels usually leads to an increase in chlorophyll concentration per cell (e.g. Cullen 1982, Veldhuis \& Kraay 2004). Hence, we may refine the interpretation of the field estimates to state that they represent maximal phytoplankton carbon for a given chlorophyll concentration under the prevailing ambient light conditions. We may expect these estimates to be modulated with changes in the available light, e.g. the carbonto-chlorophyll ratio decreasing with decreasing light. Since most of the offshore data come from depths of $40 \mathrm{~m}$ or less, the results presented here may be taken to be representative of the surface mixed layer.

\section{Carbon-to-chlorophyll ratios of phytoplankton}

The analyses presented here provide an indirect estimate of carbon-to-chlorophyll ratios in the field, based on an extensive database. They compare well with values in the literature (Table 4), and the estimates of $\chi$ that emerge from the analyses (see Fig. 3) are conservative. This relationship may be modulated by light conditions during growth, as noted above. Since most of our data are from surface and near-surface waters, we may anticipate lower values of $\chi$ at depth in the ocean, where the average light levels experienced by the cells are lower. Carbon-to-chlorophyll ratios also vary with phytoplankton group, being lowest for the larger diatom cells and highest for smaller species such as Prochlorococcus sp., which is also consistent with literature values.

The indirect method established here yields carbonto-chlorophyll ratios for phytoplankton that are reasonable, based on our current knowledge. The field data for various phytoplankton types separate into groups along the chlorophyll axis, which made it possible to establish $\chi$ for the different groups. These estimates may be considered reasonable first approximations of what can be expected in the field, when one of these phytoplankton types is dominant. It remains to be established whether these values of $\chi$ would hold if other phytoplankton types were dominant and if the nutrient and light regimes were different.

\section{Phytoplankton growth rates}

Cloern et al. (1995) used over 200 measurements of carbon-to-chlorophyll ratios and growth rates from 
laboratory cultures reported by various investigators and established an empirical model that relates carbon-to-chlorophyll ratios to growth rates based on physiological considerations. They then developed a model for conversion between carbon-based growth rates and chlorophyll-specific photosynthesis rates. Geider (1987) and Geider et al. (1997) also proposed models that account for variations in carbon-to-chlorophyll ratios based on algal responses to culture conditions. The method of Behrenfeld et al. (2005) for estimating phytoplankton growth rates for remote-sensing applications is also based on laboratory measurements. Since laboratory cultures are often maintained in conditions that poorly represent typical growth conditions at sea, some uncertainty is introduced when laboratory models are translated for application to field models.

Phytoplankton growth rates can be measured at sea indirectly, from dilution experiments on zooplankton grazing (Landry \& Hassett 1982), from chl a labelling experiments (e.g. Welschmeyer \& Lorenzen 1984), or from pigment budget experiments assuming steadystate conditions in the water column sampled (e.g. Welschmeyer \& Lorenzen 1985, Landry et al. 1995). But such measurements are not implemented on a routine basis at sea. The method applied here is based on in situ measurements of photosynthesis-irradiance parameters and an indirect estimate of carbon-tochlorophyll ratios. It allows us to exploit the existing archives of photosynthesis-irradiance parameters, and to reconcile chlorophyll-based and carbon-based models of primary production. It would be desirable to test the performance of the method presented here by using in situ experiments.

The method developed here for estimating the carbonbased growth rates of phytoplankton (Fig. 3) is based on a large body of field observations of photosynthesis-irradiance parameters and particulate carbon at sea. It is different from that proposed by Behrenfeld et al. (2005), which relies on backscattering-derived POC, with the additional assumption of a constant background contribution from heterotrophic organisms and detritus, to derive phytoplankton carbon. Their carbon-based growth model relies on culture data, whereas the photosynthesis-irradiance parameters on which our method is based are estimated for natural seawater samples from the study area. Photosynthesis-irradiance parameters are directly observable at sea, and it is now possible to extrapolate these observations on a pixel-by-pixel basis (Platt et al. 2008). Therefore, algorithms for primary production that are based on photosynthesis-irradiance formalism remain the methods of choice, compared with carbon-based models. In the absence of routine techniques to measure carbon-based growth rates for phytoplankton at sea, these rates have to be either extrapolated from laboratory observations or estimated indirectly from photosynthesis-irradiance parameters, as proposed here. At present, the value of mapping carbon-based growth rates by remote sensing is principally for comparison with growth rates used in large-scale ecosystem models. The sources of differences between models and estimates, if identified, could provide insights that would allow further improvements of both models and remote-sensing methods.

\section{CONCLUSIONS}

Almost 50 yr ago, Strickland (1960) identified limitations of existing methods for estimating the carbon-tochlorophyll ratios of natural phytoplankton. Seventeen years later, Banse (1977, p 199) lamented 'matters have not improved greatly', and identified further problems with existing methods. Now, 30 yr later, we are still in search of a robust method for measuring this elusive property. Even though new technologies such as labelled chlorophyll (see Welschmeyer \& Lorenzen 1984) have been brought to bear on the problem, such measurements have yet to become routine, and field estimates of phytoplankton carbon still often rely on the cell quotas of carbon measured in laboratory cultures, which bring their own uncertainties into the estimates. We still do not have a direct, accurate and routine method for measuring phytoplankton carbon at sea.

Meanwhile, the need to quantify phytoplankton carbon has increased. Ecosystem and climate-change models use carbon-to-chlorophyll ratios, which are known to be highly variable (values reported in the literature range from $<20$ to $>1000$; see also Table 4 for a more conservative range). We need to be able to measure the carbon-to-chlorophyll ratio directly and to understand its variability if we are to improve phytoplankton growth models and better evaluate the role of phytoplankton in the global carbon cycle and how it might vary in the context of a changing climate. It is a fundamental property of phytoplankton that remains difficult to define.

The relationships between particulate carbon and chl a presented here are based on bulk-property considerations and rely on a large body of field data. They reveal macro-ecological properties of use in models and in remote sensing. Simple ecosystem considerations then allow us to establish an upper limit for the carbon-to-chlorophyll ratio of phytoplankton in the field and its variation with chlorophyll concentration. We were also able to determine the ratios for several particular phytoplankton types, with results that are consistent with earlier observations. These findings lead to first-order estimates of the ratio from remote sensing. Once the carbon-to-chlorophyll ratio is estab- 
lished, it is easy to switch between photosynthesisirradiance models and carbon-based growth models of phytoplankton in a consistent manner, for application in remote sensing or in ecosystem models, as illustrated here.

Acknowledgements. We are grateful to 5 anonymous reviewers for their useful suggestions and comments. The present study is a contribution to the Canadian Space Agency GRIP program and to the NCEO and Oceans2025 projects of NERC (UK).

\section{LITERATURE CITED}

Banse K (1977) Determining the carbon-to-chlorophyll ratio of natural phytoplankton. Mar Biol 41:199-212

Behrenfeld MJ, Boss E, Siegel DA, Shea DM (2005) Carbonbased ocean productivity and phytoplankton physiology from space. Global Biogeochem Cycles 19:GB1006 doi:10.1029/2004GB002299

> Bricaud A, Claustre H, Ras J, Oubelkheir K (2004) Natural variability of phytoplanktonic absorption in oceanic waters: influence of the size structure of algal populations. J Geophys Res 109:C11010

Buck KR, Chavez FP, Campbell L (1996) Basin-wide distributions of living carbon components and the inverted trophic pyramid of the central gyre of the North Atlantic Ocean, summer 1993. Aquat Microb Ecol 10:283-298

Campbell L, Nolla HA, Vaulot D (1994) The importance of Prochlorococcus to community structure in the central North Pacific Ocean. Limnol Oceanogr 39:954-961

Cloern JE, Grenz C, Vidergar-Lucas L (1995) An empirical model of the phytoplankton chlorophyll:carbon ratio - the conversion factor between productivity and growth rate. Limnol Oceanogr 40:1313-1321

Collos Y (2002) Determination of particulate carbon and nitrogen in coastal waters. In: Subba Rao DV (ed) Pelagic ecology methodology. A. A. Balkema Publishers, Tokyo, p 333-341

Cullen JJ (1982) The deep chlorophyll maximum: comparing vertical profiles of chlorophyll a. Can J Fish Aquat Sci 39:791-803

Devred E, Sathyendranath S, Stuart V, Maass H, Ulloa O, Platt T (2006) A two-component model of phytoplankton absorption in the open ocean: theory and applications. J Geophys Res 111:C03011 doi:10.01029/02005JC 002880

> DuRand MD, Olson RJ, Chisholm SW (2001) Phytoplankton population dynamics at the Bermuda Atlantic time-series station in the Sargasso Sea. Deep-Sea Res II 48:1983-2003

Eppley RW, Chavez FP, Barber RT (1992) Standing stocks of particulate carbon and nitrogen in the equatorial Pacific at $150^{\circ}$ W. J Geophys Res 97:655-661

Gardner WD, Mishonov AV, Richardson MJ (2006) Global POC concentrations from in situ and satellite data. DeepSea Res II 53:718-740

Geider RJ (1987) Light and temperature dependence of the carbon to chlorophyll a ratio in microalgae and cyanobacteria: implications for physiology and growth of phytoplankton. New Phytol 106:1-34

Geider RJ, MacIntyre HL, Kana TM (1997) Dynamic model of phytoplankton growth and acclimation: responses of the balanced growth rate and the chlorophyll a:carbon ratio to light, nutrient-limitation and temperature. Mar Ecol Prog Ser 148:187-200
Goericke R, Welschmeyer NA (1998) Response of Sargasso Sea phytoplankton biomass, growth rates and primary production to seasonally varying physical forcing. J Plankton Res 20:2223-2249

Grob C, Ulloa O, Claustre H, Huot Y, Alarcon G, Marie D (2007) Contribution of picoplankton to the total particulate organic carbon concentration in the eastern South Pacific. Biogeosciences 4:836-852

Holm-Hansen O, Lorenzen CJ, Holmes JDH (1965) Fluorometric determination of chlorophyll. J Cons Int Explor Mer 30:3-15

Koenker R, Bassett G (1978) Regression quantiles. Econometrica 46:33-50

Kuninao T, Santiwat P, Kazuhiko I, Shigeru M (2000) Carbon, nitrogen, phosphorus, and chlorophyll a content of the large diatom Coscinodiscus wailesii and its abundance in the Seto Inland Sea, Japan. Fish Sci 66:509-514

> Landry MR, Hassett RP (1982) Estimating the grazing impact of marine micro-zooplankton. Mar Biol 67:283-288

> Landry MR, Peterson WK, Lorenzen CJ (1995) Zooplankton grazing, phytoplankton growth, and export flux: inferences from chlorophyll tracer methods. ICES J Mar Sci 52:337-345

Legendre L, Michaud J (1999) Chlorophyll a to estimate the particulate organic carbon available as food to large zooplankton in the euphotic zone of oceans. J Plankton Res 21:2067-2083

Loisel H, Nicolas JM, Deschamps PY, Frouin R (2002) Seasonal and inter-annual variability of the particulate matter in the global ocean. Geophys Res Lett 29:2196 doi: 10.1029/2002GL015948

Malone TC (1982) Phytoplankton photosynthesis and carbonspecific growth: light-saturated rates in a nutrient-rich environment. Limnol Oceanogr 27:226-235

Morel A (1988) Optical modeling of the upper ocean in relation to its biogenous matter content (case 1 water). J Geophys Res 93:10,749-10,768

O'Reilly JE, Maritorena S, Siegel DA, O'Brien MC and others (2000) Ocean color chlorophyll a algorithms for SeaWiFS, OC2 and OC4: Version 4. In: Hooker SB, Firestone ER (eds) SeaWiFS postlaunch calibration and validation analyses (Part 3). NASA Technical Memorandum 2000206892, 10, NASA GSFC, Greenbelt, MA, p 9-23

Oubelkheir K, Claustre H, Sciandra A, Babin M (2005) Biooptical and biogeochemical properties of different trophic regimes in oceanic waters. Limnol Oceanogr 50: 1795-1809

Platt T, Gallegos CL, Harrison WG (1980) Photoinhibition of photosynthesis in natural assemblages of marine phytoplankton. J Mar Res 38:687-701

Platt T, Sathyendranath S, Forget MH, White GN III and others (2008) Operational mode estimation of primary production at large geographical scales. Remote Sens Environ 112:3427-3448

Rogers W (1992) Quantile regression standard errors. Stata Tech Bull 2:133-137

Sathyendranath S, Platt T (2007) Spectral effects in bio-optical control on the ocean system. Oceanologia 49:5-39

Sathyendranath S, Platt T, Forget MH (2007) Oceanic primary production: comparison of models. IEEE Oceans-07 Conference Proceedings, IEEE, Aberdeen

Schoemann V, Becquevort S, Stefels J, Rousseau W, Lancelot C (2005) Phaeocystis blooms in the global ocean and their controlling mechanisms: a review. J Sea Res 53:43-66

Steele JH, Baird IE (1961) Relations between primary production, chlorophyll and particulate carbon. Limnol Oceanogr $6: 68-78$ 
Strickland JDH (1960) Measuring the production of marine phytoplankton. Bull Fish Res Board Can 122:1-172

Stuart V, Head E (2005) The BIO method. In: Hooker SB (ed) The 2nd SeaWiFS HPLC analysis round-robin experiment (SeaHARRE-2). NASA/TM 2005-212785, Greenbelt, MD, p 112

Townsend DW, Thomas M (2002) Springtime nutrient and phytoplankton dynamics on Georges Bank. Mar Ecol Prog Ser 228:57-74

Veldhuis MJW, Kraay GW (2004) Phytoplankton in the subtropical Atlantic Ocean: towards a better assessment of biomass and composition. Deep-Sea Res I 51:507-530

Editorial responsibility: Alain Vézina,

Dartmouth, Canada
Veldhuis MJW, Timmermans KR, Croot $\mathrm{P}$, van der Wagt B (2005) Picophytoplankton; a comparative study of their biochemical composition and photosynthetic properties. J Sea Res 53:7-24

Welschmeyer NA, Lorenzen CJ (1984) Carbon-14 labeling of phytoplankton carbon and chlorophyll a carbon: determination of specific growth rates. Limnol Oceanogr 29: 135-145

Welschmeyer NA, Lorenzen CJ (1985) Chlorophyll budgets: zooplankton grazing and phytoplankton growth in a temperate fjord and the Central Pacific Gyres. Limnol Oceanogr 30:1-21

Submitted: June 3, 2008; Accepted: March 5, 2009

Proofs received from author(s): May 1, 2009 